\title{
O tratamento da opcionalidade no programa minimalista*
}

\author{
Víctor M. Longa \\ Universidade de Santiago de Compostela
}

\begin{abstract}
Resumo:
A noción de opcionalidade tense aplicado tradicionalmente en Gramática Xerativa cando un mesmo conxunto léxico inicial pode orixinar libremente derivacións alternativas, obtendo cada unha delas unha diferente representación gramatical, independentemente do número de pasos precisados para chegar a cada representación. Dende o comezo da Gramática Xerativa formuláronse análises opcionais de moitas construcións alternativas. Non obstante, esta óptica cambiou drasticamente co Programa Minimalista. No presente artigo, indagarase nas razóns do tratamento tan restritivo da opcionalidade que fai este modelo.
\end{abstract}

\section{Palabras chave:}

Opcionalidade, derivación, Programa Minimalista, economía.

\begin{abstract}
:
Within Generative Grammar, the notion of optionality traditionally applies when the same initial lexical array can freely develop along alternative derivations, in such a way that different grammatical representations are obtained, no matter how many steps are needed to reach each representation. From the very beginning of Generative Grammar, optional accounts of many alternative constructions were crucially involved in the grammar. However, this view has been dramatically questioned by the Minimalist Program. In this paper, an account will be offered about the reasons and assumptions at work for the highly restrictive treatment of optionality within this framework.
\end{abstract}

Key words:

Optionality, derivation, Minimalist Program, economy.

\section{Introdución}

O Programa Minimalista da Gramática Xerativa (dende agora, PM; véxase Chomsky 1993, 1995, 2000) ten suposto unha profunda reformulación do anterior modelo, 'Government \& Binding' (en diante, GB), primeira etapa da Teoría de

\footnotetext{
"Este artigo realizouse no marco do Proxecto de Investigación "Linguas do mundo. O inventario da linguo-diversidade", desenvolvido na Universidade de Santiago de Compostela e financiado pola Xunta de Galicia (ref. PGIDTOOPXI20406PR; investigadora principal: Dra. Teresa Moure).
} 
Principios e Parámetros (Chomsky 1981). Esta reformulación atinxe, entre outros moitos aspectos, especialmente a tres, que teñen repercusións moi acusadas: por unha banda, a reconsideración da natureza paramétrica, dende macroparámetros, predominantes en GB, que tentaban caracterizar fenómenos sintácticos de amplo alcance en moitas linguas, a microparámetros no PM, centrados en pequenas diferencias localizadas no léxico e na morfoloxía; ademais, o PM supón unha aposta decidida pola indagación nos universais substantivos, fronte aos modelos previos, caracterizados por se dedicaren sobre todo aos universais formais ${ }^{1}$. En último lugar, e máis importante, o modelo minimalista defende que un enfoque representacional como o de GB non tiña a forza explicativa que se lle supuxera, adoptando no seu lugar unha visión predominantemente derivacional da gramática².

Esta perspectiva derivacional sostida polo PM, restrinxida por condicións moi estritas sobre as derivacións posibles, dispón de moitas repercusións en todos os eidos da gramática; unha delas, especialmente interesante, atinxe ao tratamento da opcionalidade nas construcións que a gramática lexitima. Tal noción de opcionalidade é intuitivamente clara: prodúcese cando unha mesma base inicial (entendida no sentido dunha mesma colección inicial de pezas léxicas, sobre as que se aplicarán os diferentes procedementos xerativos) pode tomar libremente vías derivacionais alternativas, de maneira que a partir da mesma colección léxica inicial se chega a resultados (isto é, representacións) distintos, producidos cada un deles por unha derivación diferente, ben aplicando operacións de movemento de diferente xeito en cada unha, ou ben movendo elementos nunha derivación pero non na outra. Tales posibilidades, vixentes nos modelos anteriores, son non obstante prohibidas no seo do PM, debido á alta restrición dos principios sobre os que se asenta e á propia concepción da arquitectura da teoría linguística propugnada polo devandito modelo. Por esta razón, a liberdade de antano das derivacións, resumida na noción de opcionalidade, queda vetada, exceptuando algúns casos que non atacan a economía das derivacións pretendida polo marco.

1 Tal diferencia é sinalada en Chomsky (1965: 27 e ss.). Tal como foron formulados, os universais formais consistían en condicións abstractas satisfeitas por todas as gramáticas; por exemplo, que as gramáticas de todas as linguas teñen regras transformacionais ou regras de rescritura, etc. Pola súa parte, os universais substantivos caracterizaban o feito de que os elementos de certo tipo en calquera lingua se extraen a partir dunha lista de elementos, como as categorías sintácticas ou os trazos distintivos en fonoloxía. Na visión actual, a importancia dos universais substantivos apréciase principalmente na investigación sobre as diferentes categorías funcionais.

2 Un enfoque derivacional caracterízase por pretender ofrecer un modelo das diferentes operacións necesarias para a xeración de secuencias, de maneira que tenta chegar dende un nivel de estruturación ou representación inicial a un resultado diferente, centrándose primordialmente nos mecanismos necesarios para acadar ese produto final; noutras palabras, céntrase nos mecanismos que relacionan os diferentes niveis de representación, conformando tales mecanismos as derivacións. Polo contrario, un modelo representacional baséase na atención preferente ao produto final das derivacións (as representacións gramaticais) máis que na relación (ou derivación) establecida entre os diferentes niveis de representación. Véxase Longa / Lorenzo (2001) para un estudio da alternancia entre o enfoque derivacional e o representacional en Gramática Xerativa. 
O obxectivo primordial do presente traballo consiste no estudio do aspecto sinalado, o tratamento da noción de opcionalidade no PM, especificando as asuncións e premisas segundo as cales os fenómenos opcionais non están permitidos e exemplificando as condicións que posibilitan os únicos residuos de opcionalidade (ben afastada na súa natureza, de todos os xeitos, da total liberdade de modelos previos). Ao tempo, analizaranse diferentes condicións iniciais que desbotan procesos dunha aparente opcionalidade (de feito, tratados con mecanismos opcionais en GB; véxase o apartado 2). En suma, tentarase amosar a visión tan restritiva resultante do PM, xunto aos problemas derivados dese tratamento, que fan que se afasten da facultade da linguaxe propiamente dita (do sistema computacional da linguaxe ou sintaxe) moitos aspectos que antano foran considerados no seu seo, remitíndoos a unha simple reordenación no nivel fónico.

A estrutura do artigo é a seguinte: no apartado 2 faise unha presentación xeral da noción de opcionalidade e da súa implementación, especialmente con relación ao modelo GB. O apartado 3 aborda as causas polas que o PM rexeita en xeral a opcionalidade, e no apartado 4 amósanse as únicas circunstancias que xustifican unha opcionalidade estrita (non libre, como sucedía no modelo anterior) para derivacións alternativas, xunto a outros casos de aparente opcionalidade que non é tal. Para rematar o artigo, o apartado 5 ofrece unhas reflexións sobre as consecuencias deste xiro para a teoría lingüística.

\section{Opcionalidade no modelo GB}

Dende o comezo da Gramática Xerativa, estableceuse unha clara distinción entre o status obrigatorio dalgunhas transformacións fronte ao status opcional doutras (véxase Chomsky 1956: 114, 1957: 63-64). As regras obrigatorias eran de necesaria aplicación se se quería acadar unha representación gramatical correcta (ou, noutros termos, o resultado final dunha derivación); con todo, a falta de aplicación das regras opcionais non provocaba un resultado representacional incorrecto. Vexamos un exemplo de cada tipo segundo as asuncións dos primeiros modelos xerativistas (en concreto, a Teoría Estándar e a Teoría Estándar Ampliada). Consideremos a secuencia

(1) Brais comeuno

obtida mediante a derivación pertinente. A derivación que produce (1) pode ser estendida adicionalmente para acadar a contrapartida negativa da devandita secuencia:

(2) Brais non o comeu

Para obter (2), cómpre aplicar unha regra transformacional de inclusión de negación. Posto que segundo os presupostos dos modelos sinalados (2) se obtén a par- 
tir de (1), se non se aplica a regra de inclusión de negación, (1) e máis a súa derivación seguen, de maneira evidente, a ser perfectamente lexítimas, por gramaticais. Por tanto, a inclusión da negación vén ser unha regra opcional. Non obstante, se se opta por aplicar opcionalmente esa regra, terá que actuar, esta vez de maneira obrigatoria, unha transformación de subida de clítico que antepoña este elemento ao verbo co fin de acadar a orde correcta entre os dous elementos; se non actúa esta regra de subida do clítico, o resultado será claramente anómalo, como se aprecia en

(3) *Brais non comeuno

Velaí, por tanto, a diferencia entre transformacións opcionais e obrigatorias. Deste xeito, a tarefa das regras opcionais era importante, ao permitiren diferentes derivacións alternativas ou extensións de derivacións xa acadadas; polo tanto, ao acadaren diferentes representacións finais a partir dunha mesma estrutura profunda, en dous sentidos: movendo diferentes elementos en cada caso ou aplicando pasos transformacionais adicionais ou extra (como no exemplo previo) que dan lugar a outra representación.

Tomemos unha das transformacións máis representativas de fenómenos de reordenación, a regra de extraposición (véxase D’Introno 1979, 2001 para detalles). A partir de

(4) Que veñas á escola cómpre

se actúa a regra sinalada, que dispón dun status opcional, a cláusula na posición de suxeito ('Que veñas á escola') é desprazada á dereita, ata acadar a posición final da secuencia:

(5) Cómpre que veñas á escola

Incidindo no sinalado anteriormente, nótese que unha vez que, por medio da derivación oportuna, se obtén (4), tal representación pode ser estendida de xeito opcional coa regra de extraposición; se tal regra non actúa, o resultado segue a ser gramatical. Esta constitúe a esencia do fenómeno da opcionalidade.

A diferencia entre transformacións obrigatorias e opcionais mantívose cunha plena operatividade ata o final da década de 1970. Nesa época, algúns autores moi representativos propuxeron unha reformulación importante na natureza das transformacións (motivada por cuestións teóricas vinculadas coa factibilidade da adquisición da linguaxe; véxase Longa 1999 ao respecto). Tal cambio de perspectiva consistiu en propoñer a eliminación das operacións obrigatorias, defendendo un status opcional para todas as regras; coas palabras de Chomsky e Lasnik: "The transformational rules of the core grammar are unordered and optional" (Chomsky / Lasnik 1977: 431). Esta nova visión sobre o status das regras, que proclama a opcionalidade de todas elas, anticiparía plenamente a perspectiva do modelo GB, por teren todas as regras preci- 
samente un claro status opcional no seu seo. De feito, como veremos, esta asunción concordaba por completo coa arquitectura gramatical proposta por GB.

Este modelo caracterizábase por defender unha organización altamente estruturada da facultade da linguaxe, organización baseada na mesma característica sostida para a propia relación entre a linguaxe e o resto de dominios cognitivos: a modularidade (véxase Longa / Lorenzo 1996: capítulo 1 ao respecto); do mesmo xeito en que a linguaxe tiña o status de órgano ou módulo mental, que respondía aos seus propios principios, específicos de dominio (órgano mental independente, por tanto, doutras capacidades cognitivas, aínda que interactuante con elas, en oposición clara, por exemplo, ás ideas do construtivismo de Piaget), a propia facultade lingüística era concibida como un conxunto de (sub)módulos, funcionando cada un deles como un bloque teórico encargado de dar conta, mediante diferentes principios e condicións, dun determinado aspecto da estruturación e da gramaticalidade das secuencias: por exemplo, proxección categorial (módulo X-barra), asignación de estrutura temática á estrutura sintáctica (Teoría Temática), correferencia entre frases nominais (Teoría do Ligamento), asignación de caso abstracto (Teoría do Caso) ou distancia susceptible de ser recorrida polo desprazamento dun elemento (Teoría da Acoutación), entre outros.

Respondendo ao carácter antes sinalado de aplicación opcional de operacións, cada un deses módulos tiña un status independente ata certo punto dos demais; isto significa que cada módulo era quen de sobrexerar nos seus resultados específicos, dispoñendo, polo tanto, dun poder local moi forte; con todo, esa sobrexeración local era eliminada na interactuación co resto de módulos, á hora de acadar a integración de todos os aspectos que determinaban a boa formación das secuencias. Tal interactuación obtiña no seu conxunto unha capacidade xerativa adecuada, rebaixando o poder local excesivo.

Isto mesmo pode aplicarse ao principal aspecto abordado neste traballo, as posibilidades ofrecidas pola operación de desprazamento "Móvase alfa", conformadora de derivacións en que se alteraba a disposición de partida dos constituíntes (ditada polo compoñente léxico). Fronte a regras moi específicas empregadas en modelos anteriores", "Móvase alfa", a única (metar)regra transformacional de GB, tiña un

3 Neses modelos previos (o exemplo paradigmático é a Teoría Estándar de Chomsky 1965), a competencia lingüística, coñecemento implícito da lingua por parte dun falante nativo ideal, era concibida como un conxunto de regras moi específicas e particulares, non só de cada lingua, senón de construcións concretas dentro de cada unha, co que se acadaba unha descrición precisa de tal coñecemento, coa contrapartida de que se imposibilitaban xeneralizacións significativas. Newmeyer (1996: 85) caracteriza ben o procedemento empregado en tales modelos: "In general, the author identified a construction, then formulated a transformational rule coming as close as possible to mimicking its surface characteristics: passives were derived by the passive transformation, relative clauses by the relative clause formation transformation, and so on". Por iso, segundo Hadlich (1971: 35), o número de transformacións nunha gramática completa podería chegar a varios centos. 
formato moi xeral, como se aprecia na súa propia formulación, posibilitando en principio o desprazamento de calquera constituínte a calquera posición: "muévase cualquier categoría a cualquier parte" (Chomsky 1982: 30). Non obstante, esta sobrexeración ou liberdade absoluta de actuación da regra limitábase cando a regra interactuaba co resto de módulos da facultade da linguaxe, de maneira que condicións independentes ás do propio movemento restrinxían os seus resultados, posibilitando só os gramaticais. Como sinala Radford a este respecto, "No hay nada intrínsecamente 'erróneo' en las reglas que sobregeneran, siempre y cuando esta sobregeneración sea debidamente tratada en alguna parte de la gramática. Lo único que debe preocuparnos es que la gramática global sobregenere en forma no trivial" (Radford 1981: 301-302). Deste xeito, por exemplo, o movemento dunha frase nominal só quedaba lexitimado en tanto que se producía para acadar un trazo de Caso ou un papel temático, de maneira que a absoluta liberdade de acción de "Móvase alfa" quedaba limitada ata os seus xustos termos polo enfoque modular. Tal visión, polo tanto, respondía a unha opcionalidade intrínseca na aplicación do movemento.

Este tratamento opcional das operacións era ademais moi axeitado para dar boa conta da intuición dos falantes segundo a que existen moitas construcións opcionais en cada gramática, ou o que é o mesmo, diferentes posibilidades de derivación a partir dunha mesma colección de pezas léxicas, estando tales derivacións estreitamente emparentadas (como é o caso de (4)-(5)). Xa que o cometido da gramática era, respondendo ao carácter decididamente representacional do modelo GB, lexitimar os resultados derivacionais (as representacións acadadas), a opcionalidade das regras era o terreo máis axeitado para este fin, de modo que se asumía con total naturalidade a existencia de dúas ou máis derivacións alternativas que diferiran na súa lonxitude (véxase o exemplo anterior), sen que tales diferencias fosen unha traba, sempre que cada unha delas acadase unha representación gramatical correcta. Esta perspectiva, non obstante, sería drasticamente alterada coa chegada do PM.

\section{Opcionalidade e natureza obrigatoria dos fenómenos no Programa Minimalista}

Previamente, sinalouse que o PM representa un importante cambio de énfase, dende a representación á propia derivación. Isto implica que, aínda que por descontado as representacións acadadas deben ser correctas (se ben moitas representacións gramaticais son afastadas da sintaxe; véxase o apartado 5), son os propios procesos derivacionais os que reciben no PM unha atención preferente. Deste modo, mentres en GB importaba sobre todo o resultado da derivación (chegando ás veces a lexitimarse unha derivación anómala que aínda así producía unha repre- 
sentación correcta; véxase sobre este aspecto Longa / Lorenzo 2001: 64 e ss.), no PM a complexidade (mínima) da derivación é o principal obxectivo a satisfacer. Por esta razón, o sistema computacional da facultade da linguaxe é un mecanismo centralmente marcado por estar subordinado a cuestións de economía da derivación ${ }^{4}$. Esta concepción suprime radicalmente calquera tipo de opcionalidade libre entre derivacións alternativas, asumindo a obrigatoriedade de todas as operacións (opción contraria á sostida polo modelo GB). Vexamos as razóns.

No PM formúlase unha diferencia entre trazos \{ \pm interpretables $\}$ en que descansa boa parte da concepción gramatical (véxase Chomsky 1995: 242 e ss., 2000: 75). Os trazos \{+interpretables $\}$ son, entre outros, os categoriais, polos cales unha peza léxica dada se insire nun tipo categorial determinado (Nome, Verbo, etc.), mentres que os $\{$-interpretables $\}$ son, por exemplo, trazos de Caso abstracto de elementos nominais, trazos de concordancia verbal, etc.

A diferencia entre ambos os tipos de trazos deriva das concepcións minimalistas sobre a facultade da linguaxe, fronte ás vixentes ata este modelo. No PM, a arquitectura da linguaxe concíbese do seguinte xeito: a facultade da linguaxe propiamente dita está conformada por un léxico e por un sistema computacional. O obxectivo do sistema computacional é conformar expresións (por medio de diferentes operacións de que resultan as derivacións ${ }^{5}$ ) que sexan lexibles por parte de dous niveis de interface, denominados Forma Lóxica e Forma Fónica, que constitúen os puntos de unión do sistema computacional da facultade da linguaxe cos módulos Conceptual-Intencional e Articulatorio-Perceptivo, módulos limítrofes coa linguaxe e, por tanto, externos a ela (módulos de actuación). Eses dous niveis de interface, Forma Lóxica e Forma Fónica, responden de maneira obvia a unha diferente natureza, xa que os elementos relevantes en Forma Lóxica non poden ser tratados en Forma Fónica e viceversa. Iso suxire que, nalgún momento, a compu-

4 Tal economía vén motivada por diferentes condicións que xulgan a lonxitude e outros aspectos das derivacións. Esas condicións son (1) de tipo cuantitativo ou numérico, como "Movemento máis curto" (favorece o movemento á posición máis próxima do mesmo tipo) ou "Derivación máis curta" (favorece as derivacións que dispoñen dun menor número de pasos) e (2) de tipo cualitativo, como "Avaricia" (o movemento prodúcese para a satisfacción dalgún requisito da peza afectada) ou "Demora" (prima os movementos interpretativos, no nivel de Forma Lóxica, sen efectos visibles ou fónicos; véxase a nota 7 ao respecto). En Longa / Lorenzo (2001: capítulo 4) abórdanse tales condicións.

5 Esas operacións realizadas sobre un conxunto determinado de elementos léxicos (colección léxica inicial) son basicamente: (1) Selección, pola que se toma un elemento léxico da colección e se introduce na derivación; (2) Ensamble, a misión da cal é fusionar dous elementos léxicos (por exemplo, 'a', 'nena') nun obxecto sintáctico; tal operación realízase recursivamente a vontade; (3) Concordancia, que establece unha relación de emparellamento e comprobación entre un elemento léxico concreto e un trazo nun espacio ou dominio de busca restrinxido; e (4) Movemento, operación que resulta dunha combinación de Ensamble e Concordancia, xa que establece concordancia entre un A e un B e os ensambla posteriormente mediante o movemento de B cara a A. Sobre tales operacións, véxase Chomsky (1995: 165 e ss., 2000: 82). 
tación sintáctica (a derivación) se bifurca en dous camiños: un que corresponde á computación fonolóxica e outro que corresponde á computación conceptual-interpretativa.

Unha diferencia substancial con respecto á arquitectura de GB consiste en que no modelo minimalista as diferentes condicións e principios gramaticais non responden xa a factores internos á propia linguaxe, que xorden dende o seu seo, senón que veñen motivados directamente dende as interfaces (este aspecto desenvólvese en Longa 1999, 2001 e Lorenzo no prelo), debido a que a tarefa da linguaxe é facilitar expresións lexibles a esas interfaces. Polo tanto, a linguaxe é un mecanismo que serve para relacionar os dous módulos externos con que ela mesma está vinculada, Conceptual-Intencional e Articulatorio-Perceptivo. A linguaxe é, na perspectiva do $\mathrm{PM}$, un sistema "designed to meet certain conditions imposed by other cognitive systems that the language faculty interacts with" (Belletti / Rizzi 1999: 6).

Precisamente, a diferencia entre os dous tipos de trazos, $\{ \pm$ interpretables $\}$, relaciónase coa mencionada importancia das interfaces: o cometido do sistema computacional, da linguaxe, non é outro que o de ofrecer expresións ás interfaces que sexan lexibles por elas, onde por 'lexible' hai que entender tanto os aspectos articulatorios coma os conceptuais-interpretativos, co fin de seren tales expresións interpretadas polos dous módulos externos. A diferencia entre trazos $\{ \pm$ interpretables $\}$ ten que ver, por tanto, coas diferencias xurdidas na súa interpretación: os trazos \{+interpretables\}, pola súa propia natureza, poden ser interpretados nas interfaces, non precisando de comprobación con respecto a nada. Por exemplo, cando unha expresión é ofrecida ao nivel de interface de Forma Lóxica, a interpretación categorial (o feito de que un elemento pertence á clase Verbo, outro á clase Nome, etc.) é outorgada directamente. Polo contrario, dado que os trazos \{-interpretables $\}$ non poden ser interpretados nas interfaces, necesitan ser comprobados con respecto ao trazo equivalente do obxectivo (véxase a nota 5, e infra para un exemplo) e eliminados, satisfacendo así o Principio de Interpretación Plena (Chomsky 1986), que precisamente esixe que todo elemento que chegue ás interfaces poida recibir unha interpretación neles.

Polo tanto, se unha derivación en que se atopa un trazo \{-interpretable $\}$ chega á interface de Forma Lóxica (contacto co módulo Conceptual-Intencional), a derivación creba, ao non poder ser interpretada, ou lida, polo módulo sinalado (o mesmo sucede con respecto ao outro módulo, Articulatorio-Perceptivo). Non obstante, se todos os trazos poden ser interpretados, a derivación converxerá nas interfaces, o que significa que o sistema computacional ofrece unha derivación plenamente acorde coas esixencias dos módulos limítrofes coa linguaxe.

A comprobación e posterior eliminación dos trazos \{-interpretables $\}$ antes de chegaren aos niveis de interface efectúase mediante o movemento dos elementos 
(ou trazos, en Chomsky 1995) cara ao seu dominio de comprobación (o obxectivo que teñen que acadar, ou posición de destino). Tanto o elemento afectado coma o obxectivo comparten o trazo en cuestión, quedando vinculados por medio da operación de Concordancia (véxase a nota 5) e posteriormente, mediante o movemento do primeiro (elemento afectado) á posición do segundo (destino ou obxectivo) é posible cotexar o trazo e eliminalo. Tomemos o seguinte exemplo; a estrutura

(6) Que dixeches que fixo

fórmase mediante un ascenso do 'que' obxecto de 'fixo' (xerado como complemento do verbo, no seo, polo tanto, da Frase Verbal; ese lugar márcase en (6) cunha raia) cara á posición inicial. O obxectivo deste ascenso é cotexar o trazo $\{+q u-\}$ do obxecto ('que') con respecto á posición de especificador da Frase Complementante, que dispón dese mesmo trazo $\{+q u-\}$ (tal posición é a receptora de elementos interrogativos). Mediante o movemento, o trazo do obxecto, de natureza $\{$-interpretable $\}$, queda cotexado e eliminado (a mesma dinámica repítese no resto de casos en que está envolvida un cotexo e eliminación de trazos).

Chegamos deste xeito á causa do veto da opcionalidade no PM: o movemento neste marco, como temos comprobado co exemplo de (6), non se pode concibir nin aplicar de maneira libre ou opcional, senón unicamente de maneira guiada pola necesidade de comprobar e eliminar trazos ${ }^{6}$. Polo tanto, os movementos non poden baixo ningún concepto ser opcionais, senón que están forzados pola necesidade aludida: ou ben se produce tal movemento se existe un disparador para el (se algún trazo $\{$-interpretable $\}$ ten que ser eliminado, previo cotexo) ou ben non se pode producir (se todos os trazos relevantes son $\{+$ interpretables $\}$ ).

Deste modo, o movemento é concibido no PM como un mecanismo cunha motivación que non é especificamente interna á facultade da linguaxe (tal como era a situación en GB); de feito, o papel do movemento é o de resolver deficiencias interpretativas dende a perspectiva dos sistemas limítrofes coa facultade da linguaxe, acadando unha lexibilidade plena para as expresións ofrecidas aos niveis de interface. Tal como sinala Chomsky, "la propiedad de desplazamiento está entonces impuesta del todo por las condiciones de legibilidad: la producen los requerimientos interpretativos forzados externamente por nuestros sistemas de pensamiento" (Chomsky 1998: 79).

\footnotetext{
6 Para a perspectiva sinalada, son irrelevantes as sucesivas concepcións na implementación do movemento e do seu motor: por exemplo, movemento provocado polo elemento afectado (Chomsky 1993), polo elemento afectado e máis a posición de destino (Chomsky 1995) ou pola posición de destino (mediante unha "sonda" (probe) que busca o emparellamento en relación a un obxectivo, neste caso, o elemento susceptible de ser afectado polo desprazamento) como se expón en Chomsky (2000).
} 
Este movemento ou desprazamento ten carácter universal, se ben as linguas difiren con respecto ao momento en que se aplica: ou ben na sintaxe aberta, con efectos visibles (por se producir antes do punto de materialización ou spell-out en que a derivación se bifurca na computación fonolóxica e na conceptual) ou ben na sintaxe encuberta, no nivel de Forma Lóxica, de maneira que os seus efectos non son apreciables fonicamente, por se producir tal movemento despois da devandita bifurcación, co cal a computación fonolóxica non se pode ver afectada ${ }^{7}$. Segundo Chomsky (1993, 1995), os desprazamentos sen efectos fónicos son preferibles por disporen dun carácter máis económico (xa que non implican o paso extra de arrastre de material fónico).

Non obstante, posto que non todas as operacións son encubertas (lembremos a secuencia (6), en que se produce un movemento visible, cun desprazamento en sintaxe aberta do 'que'), ten que haber algunha razón para a existencia das operacións

7 A diferencia entre movementos visibles e non visibles pode apreciarse cun exemplo clásico referido ao ámbito (scope) dos cuantificadores; tomemos

Alguén coñece cada lingua humana

Esta secuencia é ambigua, porque pode ter dúas lecturas: (1) hai alguén tal que ese alguén coñece todas as linguas (un só individuo), e (2) para cada lingua, hai polo menos unha persoa (diferente en cada caso) que coñece esa lingua. Cada unha das dúas interpretacións depende de que elemento (ben 'alguén', ben 'cada lingua humana') ten un ámbito máis amplo, quedando o outro cun ámbito máis restrinxido. Pero debe notarse que só existe unha estrutura superficial, que corresponde á lectura (1). A lectura (2) acádase precisamente no nivel de Forma Lóxica, mediante un movemento (ascenso de cuantificador) de 'cada lingua humana', de maneira que se sitúe á esquerda de 'alguén', obtendo así un ámbito máis amplo. Ao se producir tal movemento no nivel de Forma Lóxica, é encuberto.

Este mecanismo de movemento encuberto é en esencia o mesmo que sucede en linguas como o chinés cos elementos interrogativos (fenómeno coñecido como 'qu- in situ'). Fronte a linguas como o galego, onde os pronomes interrogativos deben moverse en sintaxe aberta (lémbrese o caso de (6)), en chinés os elementos interrogativos non abandonan a posición en que son xerados, como se aprecia en

Zhangsan yiwei Lisi mai-le shenme?

Zhangsan pensa Lisi mercar-PAS que

‘Que pensa Zhangsan que mercou Lisi?’ (Huang 1995: 149)

Tomemos agora estoutra secuencia:

Zhangsan xiang-zhidao Lisi mai-le shenme

Zhangsan pregúntase Lisi mercar-PAS. que

'Zhangsan pregúntase que mercou Lisi' (Huang 1995: 149)

A pesar da aparencia moi semellante de ambas as secuencias chinesas (o mesmo elemento interrogativo 'shenme' aparece na mesma posición nas dúas secuencias, como obxecto de 'mai'), a interpretación é moi diferente en cada caso: tal diferencia débese precisamente ao diferente ámbito de 'shenme'. Na primeira secuencia, o seu ámbito esténdese sobre toda a oración, pero na segunda o ámbito restrínxese á secuencia incrustada ('...Lisi mai-le shenme'). Para dar conta desa diferencia, proponse un movemento do elemento tal que se sitúa en cada caso na posición dende a que poida tomar o ámbito axeitado: posición inicial da secuencia matriz e posición inicial da incrustada respectivamente. Como se apreciará, ese movemento non é visible, senón encuberto, acadado precisamente no nivel de Forma Lóxica. 
visibles. Chomsky $(1993,1995,1998)$ defende que esa razón atinxe á diferente natureza dos trazos vinculados co movemento: natureza fraca fronte a forte. Os trazos fracos non son visibles no nivel de Forma Fónica, polo que non estorban as operacións feitas nese nivel e non precisan ser eliminados. Pola contra, os trazos fortes son visibles en Forma Fónica, razón por que deben ser eliminados antes de que a derivación entre na fase de computación fonolóxica; en caso contrario, a derivación crebaría ao chegar á interface.

Tomemos un exemplo que amose esa diferente natureza fraca/forte, vinculado coa diferencia entre linguas que amosan unha orde básica suxeito-verbo-obxecto (como o galego) fronte a outras cunha orde básica verbo-suxeito-obxecto (tal é o caso do galés). Consideremos as seguintes secuencias, tiradas de Hendrick (1994: 179):

(7) Brais viu a nena

(8) Gwelodd Gareth y ferch ver-PAS. Gareth a nena

'Gareth viu a nena'

A diferencia entre (7) e (8) pódese atribuír á natureza forte e fraca respectivamente do trazo presente na Flexión (no nodo Tempo), que debe comprobar o cumprimento do Principio de Proxección Ampliado, segundo o cal toda secuencia debe ter un suxeito (véxase Chomsky 1982: 24). Asumindo a seguinte estrutura para esas secuencias (de que se omite, para simplificar, a proxección categorial do verbo lixeiro (light verb); véxase Chomsky 2000: 82):

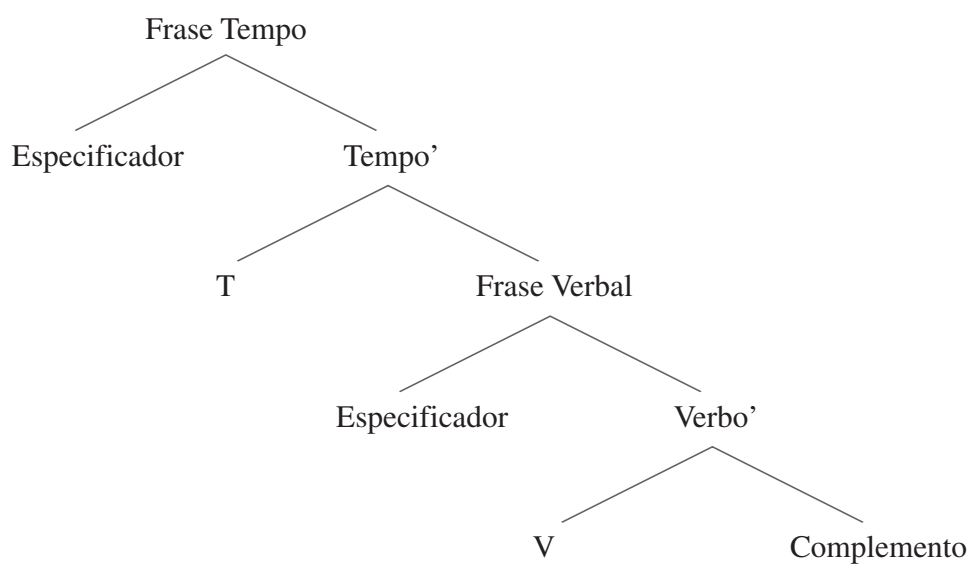


en galego o trazo sinalado dispón dun carácter forte, o que implica satisfacer o Principio de Proxección Ampliado mediante un movemento visible do argumento externo ('Brais', xerado na posición de especificador da Frase Verbal; véxase o esquema) á posición de suxeito da secuencia (especificador de Frase Tempo), suprimíndose o trazo tras ser cotexado. En caso contrario, crebaríase o Principio de Interpretación Plena, ao chegar á interface un elemento que non podería recibir interpretación. Non obstante, no exemplo galés ese mesmo trazo é fraco, co cal o argumento externo ('Gareth') se move á posición de suxeito para comprobar o trazo non na sintaxe aberta, senón no nivel de Forma Lóxica, de maneira encuberta, sen que exista un arrastre fónico; noutras palabras, só con efectos interpretativos.

Tras esta exposición, e retomando o aspecto previo, independentemente da natureza fraca ou forte do trazo en cuestión, o movemento está motivado pola necesidade de comprobar un trazo: se nos dous exemplos o movemento (ben aberto, ben encuberto) non se aplica, a derivación fracasa ${ }^{8}$. Por isto, no PM o movemento concíbese como un proceso obrigatorio, disparado ou provocado por un trazo, polo que se exclúe a posibilidade de movementos opcionais libres. Como sinala Zwart, "Ideally, a trigger "forces" movement, excluding the possibility of optional movement" (Zwart 1998: 367).

\section{Lexitimidade de fenómenos opcionais no PM}

Así pois, a situación con respecto á opcionalidade no PM é ben diferente da que se producía en GB; neste modelo, a opcionalidade abranguía tanto as propias regras como as derivacións por elas conformadas: había liberdade absoluta para aplicar ou non unha regra, co que tamén existía esa mesma liberdade para conformar derivacións alternativas, o único requisito das cales era conducir a un resultado representacional correcto. Pola contra, no PM as regras non son opcionais, como se expuxo, senón de forzada aplicación, polo que se elimina a propia esencia do fenómeno de opcionalidade. A facultade da linguaxe vólvese como consecuencia moito máis restritiva (véxase o apartado 5) porque só se posibilitan aquelas derivacións en que está envolvida a comprobación e eliminación dun trazo do sistema de Concordancia. Tal concepción resulta nunha eliminación da maior parte das derivacións alternativas para unha mesma estrutura profunda; ademais do aspecto sina-

\footnotetext{
8 Ao igual que outras linguas románicas, o galego é unha lingua de inversión libre suxeito-verbo, o que significa que en principio a existencia de derivacións alternativas con e sen inversión (do estilo de 'chamou o rapaz' e 'o rapaz chamou') semella cuestionar a obrigatoriedade sinalada para o movemento en secuencias como (7). Non obstante, no apartado 4 ofrécese unha análise que non compromete a aplicación obrigatoria do desprazamento, baseándose tal análise nunha colección diferente de pezas léxicas para a inversión e a non-inversión.
} 
lado de perda de liberdade nas derivacións, esta visión implica igualmente que se perde (de xeito consciente) a captación por parte do modelo da intuición dos falantes sobre a estreita relación existente entre moitas parellas de construcións, como (4)-(5). Naturalmente, o sinalado non significa caracterizar como agramaticais secuencias claramente pertencentes ao coñecemento da lingua, como (5); aínda así, tales secuencias son afastadas do sistema computacional, sendo remitidas a unha simple reordenación no nivel de Forma Fónica.

Deste modo, no PM non poden producirse derivacións sintácticas alternativas libres a partir dunha mesma colección léxica inicial (e se se produciren, son afastadas da sintaxe propiamente dita). Dadas as premisas estritas do modelo, as únicas posibilidades que lexitiman derivacións alternativas no PM (opcionalidade matizada, pero non libre) son as seguintes:

A. Partir de diferentes coleccións léxicas iniciais, de modo que ao estaren implicados dous conxuntos de pezas léxicas, a opcionalidade non é senón aparente, porque cada unha das derivacións ten o seu propio input.

B. No caso de que dúas derivacións partan dunha mesma colección léxica inicial, a opcionalidade só estaría lexitimada sempre que existisen dous trazos alternativos (ou dúas maneiras diferentes de comprobar o mesmo trazo) e que a comprobación fose igualmente económica, dende unha destas dúas premisas:

B.1. A derivación $\mathrm{W}$ que parte da colección léxica $\mathrm{Y}$ ten exactamente o mesmo número de pasos que a derivación alternativa $\mathrm{Z}$, o input da cal é tamén esa mesma colección léxica inicial Y (economía global).

B.2. As dúas derivacións dispoñen dun diferente número de pasos, se ben cada un destes pasos satisfai estritamente os criterios de economía para o movemento (economía local).

A continuación desenvolveranse estas diferentes posibilidades, exemplificándoas mediante fenómenos ben coñecidos da nosa lingua.

\subsection{Diferentes coleccións léxicas iniciais}

Unha lingua é basicamente un medio de relacionar sons con significados, pero, de xeito evidente, a relación entre ambos os planos debe ser compatible, polo que, segundo Chomsky (1995: 164), cada un deles ten que se basear nunha mesma elección de elementos léxicos. Por esta razón, tal elección é o primeiro paso do procedemento xerativo: o conxunto inicial dos elementos léxicos, ou colección léxica, será entregado posteriormente ás diferentes operacións do sistema computacional (véxase a nota 5). 
Tal como se sinalou antes, no modelo GB unha mesma colección léxica podía optar libremente por vías derivacionais diferentes, podendo mesmo tal colección ser modificada no transcurso da derivación (engadindo ou suprimindo elementos; véxase infra). Tal capacidade é inviable no PM, xa que moitas derivacións alternativas quedan desbotadas. Con todo, se tales derivacións alternativas parten de dúas coleccións léxicas diferentes, os criterios de economía non se verán obrigados a decidir entre ambas, polo que non sancionarán ningunha delas como susceptible de ser rexeitada ou remitida fóra da sintaxe, ao non ser a súa base a mesma. Consideremos as derivacións alternativas, aparentemente opcionais, da nota 8:

(9) O rapaz chamou

(10) Chamou o rapaz

Lembremos que en relación a (7) (o cal se pode estender a (9)), o trazo que se debe comprobar para satisfacer o Principio de Proxección Ampliado ten carácter forte en galego, razón pola que o suxeito ('Brais' e 'o rapaz' respectivamente en (7) e (9)), xerado na posición de especificador da Frase Verbal, debe ascender ata a posición de especificador de Frase Tempo, onde se realizará a comprobación e eliminación do trazo.

Non obstante, o galego, coma outras linguas románicas (italiano, castelán, catalán, entre outras) é unha lingua de inversión libre (véxase Rizzi 1982), polo cal tamén (10) ten un status perfectamente gramatical. As linguas que amosan este fenómeno coñécense como 'pro-drop', caracterizándose, ademais de pola sinalada inversión, pola posibilidade de que exista un suxeito fonoloxicamente nulo ou polo feito de que o suxeito dunha secuencia pasiva poida estar en posición posverbal, como se amosa en:

(11) chamou

(12) foi chamado o rapaz polo seu pai

Tales características, pola contra, son inaccesibles a linguas como inglés ou francés.

Tendo en conta que o modelo GB era o dominio por excelencia da opcionalidade, segundo as súas premisas asumíase unha mesma base ou colección léxica para as dúas construcións alternativas con e sen inversión ((9)-(10)), derivándose os casos con inversión (orde verbo-suxeito, como (10)) a partir da orde suxeito-verbo, como (9). Segundo Rizzi (1982) as propiedades sinaladas poden ser explicadas mediante o parámetro do suxeito nulo: tal parámetro especifica a posibilidade en linguas como o galego (e imposibilidade respectiva en inglés) de que o verbo, máis concretamente a súa flexión, lexitime un pronome baleiro de contido fonolóxico (pero 
activo sintáctica e interpretativamente) en posición de suxeito cando esta posición non está ocupada por un suxeito léxico; esta é a razón de que o suxeito léxico poida abandonar a súa posición orixinal preverbal, desprazándose ata ocupar a posición posverbal por medio dunha adxunción á dereita da Frase Verbal, como se amosa en:

$$
\begin{aligned}
& \text { FRASE FLEXIÓN [o rapaz FLEXIÓN } \\
& \text { FRASE FLEXIÓN [pro FLEXIÓN } \\
& \text { FRASE VERBal }
\end{aligned}
$$

A análise exposta baseábase na opcionalidade das dúas secuencias (con e sen inversión), do seguinte xeito: se o suxeito léxico é invertido, a súa posición queda ocupada polo pronome baleiro, lexitimado pola riqueza da flexión, polo cal se pode comprobar que a colección léxica inicial pode ser alterada mediante a introdución dese pronome cando o suxeito léxico abandona a posición preverbal.

Non obstante, tal análise está vetada no PM. Dende as premisas deste modelo, as bases iniciais das dúas estruturas están conformadas por unha colección léxica diferente en cada caso; tales coleccións son, respectivamente para a secuencia sen e con inversión, as seguintes (simplificadas en detalles para maior claridade, omitíndose a numeración correspondente; por outro lado, téñase en conta que as coleccións non están ordenadas, producíndose a ordenación con posterioridade á sintaxe, no compoñente fonolóxico):

(15) $\{$ o, rapaz, chamar $\}$

(16) $\{$ pro, chamar, o, rapaz

As dúas coleccións léxicas expostas, aínda que coincidentes na súa meirande parte, diverxen na ausencia e presencia respectiva do pronome 'pro', co que existe unha diferencia (non só sintáctica, senón tamén a efectos interpretativos) que lexitima cada derivación, impedindo que entren en conflito. Deste modo, ao non existiren dúas derivacións conformadas dende unha mesma colección léxica inicial, non hai senón aparencia de opcionalidade?

9 Aínda así, as conclusións ao respecto poden variar moito dependendo das asuncións manexadas nas diferentes análises. Por exemplo, Barbosa (1997), seguindo as liñas xerais desenvolvidas na súa (1995), propón unha análise en que a posición subxacente real do suxeito léxico é a posverbal, o que dá conta da orde verbo-suxeito (inversión); polo tanto, na posición preverbal está presente o pronome baleiro 'pro'. Pola súa parte, as construcións con orde suxeito-verbo, sen inversión, son obtidas ben mediante a xeración do suxeito léxico nunha posición (non canónica) de adxunto á Frase Flexión (semellante á dislocación de clítico á esquerda) ou ben mediante movemento de foco do suxeito dende a posición base, posverbal, ata quedar situado na preverbal. Debe notarse que, nestes casos, a orde suxeito-verbo non se pode obter no propio sistema computacional, senón como un proceso de reordenación fonolóxica. 
Outro caso que segue as mesmas liñas é o dos expletivos; Chomsky (2000) propón en relación á alternancia entre presencia e ausencia do expletivo en certas construcións inglesas unha análise baseada en diferentes coleccións léxicas en cada caso; considérese

(17) I expected there to be a proof discovered eu esperaba expl. inf. haber unha proba descuberta

(18) I expected a proof to be discovered eu esperaba unha proba inf. haber descuberta 'esperaba que se descubrise unha proba'

(Chomsky 2000: 85)

A diferencia entre estas dúas secuencias reside en que en (17) se ensambla o expletivo, mentres que en (18) se despraza 'a proof' dende a súa posición orixinal (véxase (17)) ata se colocar á esquerda do infinitivo 'to be'. Pois ben, o importante consiste en que esa elección non é libre, senón que "depende de que esté o no disponible un expletivo en la colección léxica inicial” (Chomsky 2000: 85). Tal análise pode ser aplicada aos elementos expletivos do galego (véxase Álvarez / Regueira / Monteagudo 1986: 169, e Silva-Villar (1998) para unha análise de expletivos de diferentes linguas, galego incluído, dende presupostos minimalistas). Aínda que, tal como indican Álvarez / Regueira / Monteagudo (1986: 521), en galego non existe normalmente este tipo de elementos, a diferencia do inglés, onde o seu uso está xeneralizado, en certos casos e contextos os expletivos poden aparecer; por exemplo,

(19) E el é sabido que para que esta planta teña todo o seu poder é preciso (...)

(20) El chove

(Álvarez / Regueira / Monteagudo 1986: 169)

A alternancia entre (19)-(20) e os seus correlatos sen expletivo non é libre, seguindo as liñas esbozadas na análise de Chomsky, senón que depende da escolla léxica inicial; en (20), o expletivo, ao estar dispoñible nesa escolla inicial, pode ensamblarse co resto de elementos para conformar a devandita secuencia; non obstante, na variante sen expletivo ('chove') tal opción non se pode producir. Polo tanto, como sucedía no exemplo previo da orde suxeito-verbo, a opcionalidade que mostran as variantes con e sen expletivos é só aparente.

\subsection{Derivacións igualmente económicas}

Se en 4.1 se amosaron derivacións aparentemente opcionais, pero que en realidade remitía cada unha delas a un diferente input, neste subapartado analizaranse os únicos casos de opcionalidade permitidos polo modelo PM, dadas as súas premisas 
(opcionalidade que, como xa sinalei, non é libre, senón estritamente dependente da comprobación de trazos). Nestes casos, teñen que existir dous trazos alternativos, un para cada unha derivación, ou dúas maneiras distintas de comprobar o mesmo trazo. Con todo, para seren lexitimadas tales derivacións alternativas, a comprobación deses trazos debe ser igualmente económica dende a perspectiva da complexidade computacional da derivación, polo que deben aterse a férreos mecanismos de control. Tal control ten que ver con dúas posibilidades, anticipadas antes (véxase a nota 4): economía global (dúas derivacións co mesmo número de pasos en cada unha delas) ou economía local (dúas derivacións que poden diverxer no respectivo número de pasos, aínda que cada paso ten que se ater a estritos criterios de economía, como fundamentalmente 'Movemento máis curto'). A continuación veremos un exemplo de cada un destes enfoques ${ }^{10}$.

\subsubsection{Economía global}

A primeira posibilidade para lexitimar derivacións alternativas para unha mesma colección léxica inicial consiste en que cada unha desas derivacións teña exactamente o mesmo número de pasos que o resto de derivacións. Como exemplo de economía global, tratarase a análise da orde entre clítico e elemento verbal en galego en secuencias de infinitivo invariable, desenvolvida en Longa / Lorenzo (no prelo) (e simplificada nos aspectos non directamente relevantes para a argumentación).

Como é ben sabido, a posición por defecto dos clíticos nas oracións temporalizadas (matrices) en galego é a énclise (orde verbo-clítico) pero a mediación dalgúns factores (como a presencia dunha partícula negativa ou interrogativa, de certos adverbios ou a inserción do clítico nunha secuencia incrustada) leva necesariamente á anteposición do clítico con respecto ao verbo, ou próclise (orde clíticoverbo; véxase Álvarez / Regueira / Monteagudo 1986: 183 e ss.).

En Rouveret (1992) analízase a orde dos clíticos en portugués europeo, propoñendo unha posición específica de xeración de clíticos, a proxección W(ackernagel), situada por enriba da proxección de concordancia (tal análise é estendida en Longa / Lorenzo (no prelo) ao asturiano e ao galego). Segundo Rouveret, dada a natureza verbal e nominal dos clíticos, o núcleo desa proxección, W, proxecta un dominio que serve para efectuar a comprobación dun elemento de carácter verbal e outro de carácter nominal. A comprobación do elemento de carácter verbal faise coa adxun-

${ }^{10}$ As dúas alternativas, economía global e local, están actualmente en loita, existindo argumentos para as dúas ópticas, se ben, moi recentemente, Chomsky (2000: 79-80) ten defendido a preferencia pola economía local, que permite unha simplificación da natureza dos procedementos gramaticais (véxase Longa / Lorenzo 2001: 95 e ss. sobre as repercusións desa simplificación). Por outro lado, véxanse Kitahara (1997) e Collins (1997) como traballos máis representativos do enfoque global e local respectivamente. 
ción do complexo verbal (producido tal complexo polo ascenso sucesivo da peza léxica verbal, xerada como núcleo da Frase Verbal, ás proxeccións de tempo e concordancia, co fin de ir recollendo os trazos propios desas proxeccións), adxuntándose o complexo á esquerda do clítico. Pola súa parte, por medio da comprobación do elemento de natureza nominal, o suxeito oracional (xerado internamente á Frase Verbal, na posición de especificador) elévase cara á posición de especificador da proxección máxima, Frase W. Deste xeito, obtense a énclise (verbo-clítico).

Non obstante, cando por riba dos núcleos flexivos (concordancia e tempo) existen outros núcleos, como negación, foco ou o complementante introdutor de secuencias subordinadas entre outros, W non se xera, polo que este núcleo non proxecta o seu dominio. Neste caso o complexo verbal adxúntase ao núcleo de concordancia, facendo o propio o clítico de seguido (ascendendo dende posicións argumentais), de maneira que este elemento se adxunta á esquerda do complexo (verbotempo-concordancia), co que resulta a próclise (orde clítico-verbo). Do referido contraste deriva a orde relativa producida en secuencias como

(21) Fíxoo

$$
\begin{aligned}
\text { (22) a } & \text { Non o fixo } \\
\text { b. } & \text { Xa o fixo } \\
\text { c. } & \text { Dígolle que o fixo }
\end{aligned}
$$

No que respecta ás secuencias sen tempo, de infinitivo, a posición do clítico é máis libre, mesmo en presencia dos factores que levan obrigatoriamente á próclise nas secuencias con tempo. É o caso, por exemplo, da alternancia producida en

(23) É mágoa non facelo

(24) É mágoa non o facer

Segundo o dito antes, dada a presencia en (23)-(24) dunha partícula negativa, W non se proxecta, polo que a diferencia entre as dúas secuencias non pode ser atribuída a diferentes coleccións léxicas iniciais en cada caso; só é posible unha mesma colección léxica, en que W non está presente. Polo tanto, xa que as dúas derivacións deben partir do mesmo conxunto de elementos, esas derivacións, segundo as premisas do PM, deben ser igualmente económicas.

A análise desenvolvida en Longa / Lorenzo (no prelo) para lexitimar as dúas computacións alternativas baséase na economía global, de maneira que ambas teñen un mesmo número de pasos. No caso de (24), prodúcese un movemento do complexo verbal (verbo-tempo) de modo que se adxunta ao núcleo de concordancia, facendo de seguido o mesmo o clítico. Posteriormente, o núcleo de concordancia, xunto aos elementos adxuntados a el, ascende ata o de negación, onde o complexo comproba o 
trazo correspondente. Mediante esta derivación obtense a próclise (clítico-verbo; a adxunción do clítico, como no resto de adxuncións, sitúa o clítico á esquerda do complexo). Pola súa parte, no que atinxe a (23), prodúcese un movemento do complexo verbal, como no caso anterior, cara á posición nuclear de concordancia (con posterior subida á posición de negación); a diferencia reside en que o clítico non se adxunta ao complexo, co que permanece en posición posverbal, derivándose a énclise (verbo-clítico). A diferencia entre ambas as derivacións pode reducirse á contraposición que Roberts (1991) establece entre o 'dominio morfolóxico' e o 'dominio sintáctico' dunha proxección. A adxunción ao dominio morfolóxico serve para lexitimar a forma dunha palabra, mentres que o movemento ao dominio sintáctico é independente desa lexitimación. A opcionalidade de (23)-(24) deriva precisamente de que o infinitivo invariable non precisa comprobar a súa forma con relación aos trazos propios da concordancia, co que xorden dous itinerarios alternativos para comprobar o trazo derivado da negación: ou ben adxuntarse ao dominio morfolóxico do núcleo de concordancia, a que despois se adxunta o clítico (próclise), ou ben adxuntarse ao dominio sintáctico dese núcleo, por enriba da posición que ocupa o clítico, que queda no dominio morfolóxico da concordancia. Do sinalado deriva a alternancia entre as dúas derivacións, que, segundo as premisas discutidas, son igualmente económicas, precisando do mesmo número de pasos (dous) en cada caso.

\subsubsection{Economía local}

A segunda posibilidade de lexitimar derivacións alternativas para unha mesma colección léxica inicial consiste na asunción de que non é estritamente necesario que dúas derivacións amosen o mesmo número de pasos. Segundo Collins (1997), a gramática non ten que computar o número de pasos das derivacións alternativas, rexeitando posteriormente a menos económica. No seu lugar, propón unha economía estritamente local, consistente en que cada paso derivacional en si mesmo ten que ser o máis económico posible. Ofrezo un exemplo tratado en Collins (1997) e adaptado para o galego.

A construción coñecida como 'inversión de locativo' caracterízase polo feito de que cando un argumento locativo aparece en posición preverbal (en primeira posición) cómpre facer a inversión suxeito-verbo; véxase o seguinte contraste:

(25) As mulleres estaban xunto á figueira

(26) Xunto á figueira estaban as mulleres

Se non se produce a inversión, o resultado é claramente anómalo, como amosa (27):

(27) *Xunto á figueira as mulleres estaban 
Para (25) e (26) hai que asumir unha mesma colección léxica; non obstante, a derivación non invertida de (25) e a invertida de (26) amosan unha diferente lonxitude derivacional. Con respecto a (25), simplificando detalles, o suxeito, xerado como no resto de casos no seo da Frase Verbal, debe ascender para ocupar a posición máis alta de especificador (correspondente á proxección Frase Tempo). Tal ascenso satisfai ao tempo dous diferentes requisitos: por un lado, a necesidade, ditada polo Principio de Proxección Ampliado, de que a posición de suxeito oracional quede enchida na sintaxe aberta; por outro, mediante ese mesmo ascenso do argumento externo, tal argumento comproba e elimina o seu trazo de caso nominativo con respecto ao núcleo flexivo da oración. Por tanto, un mesmo paso computacional serve para a satisfacción de dous requisitos. Diferente é a situación de (26): a anteposición do argumento locativo serve para encher a posición de suxeito oracional na sintaxe aberta, pero ese movemento non serve para comprobar e eliminar o trazo de caso nominativo; para iso, cómpre un movemento do argumento externo ('as mulleres') no nivel de Forma Lóxica (movemento non visible, interpretativo).

Polo tanto, a derivación invertida (26) está conformada por un paso máis que a non invertida (25), co cal se esperaría que a economía global vetase a menos económica (26) por agramatical, o que evidentemente non é o caso. Polo contrario, o criterio de economía local serve para dar conta deste contraste; aínda que unha das derivacións envolve un paso máis, cada paso respecta os principios en que se basea a economía local (fundamentalmente, aquel que impón que cada movemento sexa o máis curto posible; véxase a nota 4 ).

\section{Repercusións para a facultade da linguaxe}

Facendo unha recapitulación, no modelo GB as regras de desprazamento eran de aplicación totalmente libre, polo que tamén as derivacións amosaban unha liberdade absoluta. Non obstante, o PM cambia drasticamente esta situación, de xeito que se abandona a opcionalidade nun dobre nivel: por un lado, na propia natureza das operacións de movemento, forzadas pola comprobación de trazos; por outro, esa falta de liberdade na aplicación das regras recorta fortemente a liberdade das derivacións. Polo tanto, pásase dunha situación en que derivacións alternativas quedaban lexitimadas sen importar o número de pasos de cada unha con tal de que acadasen unha representación correcta a outra en que dúas derivacións alternativas só estarán lexitimadas (1) se hai en cada unha un trazo \{-interpretable $\}$ que debe ser comprobado, e (2) se amosan a mesma economía computacional (ben global, ben local).

Como se mencionara, nunha lingua existen moitos pares de secuencias moi relacionadas (lémbrese (4)-(5)) en que, na maior parte de casos, unha das derivacións é conformada estilisticamente a partir da outra, co que non hai un trazo nela que precise comprobación: isto envolve a maior parte das construcións que semellan ter 
dúas derivacións posibles que parten da mesma estrutura léxica inicial. É o caso, por exemplo, de (5), en que se aplica unha extraposición (movemento á dereita) a misión da cal non atinxe á comprobación de ningún trazo no sistema computacional. Podemos pensar noutros moitos exemplos:

(28) Regalei as flores a María

(29) Regalei a María as flores

(30) Fuches a Cangas no barco

(31) Fuches no barco a Cangas

(32) Os meus dous curmáns

(33) Os dous meus curmáns

((32)-(33): Álvarez / Regueira / Monteagudo 1986: 217)

A primeira parella amosa unha alternancia de orde entre o obxecto directo e o indirecto, mentres que a segunda fai o mesmo entre un locativo e un adxunto. Pola súa parte, (32)-(33) mostra a liberdade de colocación dun posesivo con respecto a un numeral. Nestes casos, unha das derivacións confórmase estilisticamente, non habendo ningunha comprobación de trazos implicada. A conformación de tales estruturas ten que ver unicamente con factores de tipo pragmático, independentes do sistema computacional da linguaxe (véxase non obstante Zwart 1998, onde se formula unha crítica a esa visión, segundo a que o cotexo de trazos pode estar implicado nalgúns fenómenos discursivos). Lembremos que, segundo Chomsky (1995, 2000), os trazos non interpretables son o mecanismo que dispara o movemento producido no sistema computacional. Por tanto, na maior parte de derivacións alternativas, en que non existe comprobación de trazos, tales movementos non son tratados na facultade da linguaxe, ao non responderen á idea do que é computacionalmente simple. Non estraña, así, a seguinte reflexión de Culicover: "According to the approach of Chomsky's abstract minimalism, the scope of "syntax" is highly restricted, and much of what appears to be uncontroversially syntactic turns out no to be syntactic at all" (Culicover 1998: 52).

Esa distinción entre fenómenos sintácticos e outros que non o son aparece de feito explicitamente tratada en Chomsky:

En la primera gramática transformacional se hacía a menudo una distinción entre las reglas «estilísticas» y las otras. La distinción parece ser cada vez más real. [...] las propiedades computacionales centrales difieren en su carácter de una manera muy marcada de otras muchas operaciones de la facultad del lenguaje, y [...] puede ser un error integrarlas dentro de la misma estructura de principios (Chomsky 1995: 315). 
Tendo en conta isto, xorde unha cuestión obvia: tomando o caso da extraposición, ou as parellas recollidas en (28)-(33), as reordenacións de cada par non entran na sintaxe propiamente dita; con todo, non é menos certo que non deixan de ser secuencias correctas, que un falante recoñece inequivocamente como pertencentes á súa lingua. A solución de Chomsky consiste en remitir tales secuencias ao compoñente fonolóxico, sendo meros fenómenos de reordenación no nivel fónico ${ }^{11}$, interface co módulo Articulatorio-Perceptivo.

Unha idea central do PM consiste na súa defensa dun deseño perfecto para a linguaxe (sistema computacional). De feito, Chomsky (2000: 76) propón a Tese Minimalista Máis Forte: "El lenguaje es una solución óptima a las condiciones de legibilidad". A tese defende que o deseño da linguaxe pode achegarse a unha solución perfecta a especificacións mínimas de deseño (isto é, a solución conceptualmente máis sinxela como medio de unión entre os módulos Conceptual-Intencional e Articulatorio-Perceptivo). Esa perfección significa que a facultade debe amosar condicións de lexibilidade, de maneira que outros módulos (os dous externos sinalados) poidan acceder ás expresións xeradas, mediante a lexibilidade de tales expresións nos niveis de interface.

Como se sinalou, os desprazamentos débense á necesidade de comprobar e eliminar trazos non interpretables. Isto implica que se non se cumpren as condicións tan restritivas que poden permitir a opcionalidade (non libre, como en GB, senón disparada pola necesidade de eliminar un trazo), os movementos do estilo da extraposición non están motivados pola necesidade de lexibilidade nas interfaces; esta é a verdadeira razón de que tales movementos e, polo tanto, a opcionalidade libre, sexan rexeitados na visión estrita da sintaxe: reordenacións como as sinaladas, a maior parte dos casos de opcionalidade, atentan precisamente contra ese deseño perfecto ansiado, ao non responderen ás especificacións mínimas de deseño.

Tal perspectiva semella extrema, tendo en conta a contraposición establecida entre a linguaxe propiamente dita (léxico e sistema computacional) por un lado e os módulos limítrofes coa linguaxe por outro. Mentres a linguaxe amosa segundo o PM un deseño perfecto, xa que nada é redundante, os dous módulos externos teñen un carácter moi imperfecto. Neste sentido, estes módulos serían unha especie de recipiente do lixo aos cales se remite todo aquilo que compromete a perspectiva desa suposta perfección. En suma, a opcionalidade representa unha desviación máis con respecto ao deseño perfecto; por tal razón é rexeitada.

${ }^{11}$ Como sinala Culicover (1998: 74, n. 6), defender que operacións como a extraposición son dende a óptica do PM meras reordenacións xestadas no nivel de Forma Fónica, non na sintaxe, non altera ningunha das propiedades de tales construcións, senón que só cambia o que se entende por sintaxe ou por Forma Fónica. 


\section{Referencias Bibliográficas}

Álvarez, R. / X. L. Regueira / H. Monteagudo (1986): Gramática galega (Vigo: Galaxia).

Barbosa, P. (1995): Null Subjects, Tese de Doutoramento (Cambridge, Mass: MIT).

Barbosa, P. (1997): "Subject Positions in the Null Subject Languages", Seminarios de Linguística, 1: 39-63 (Faro: Universidade do Algarve).

Belletti, A. / L. Rizzi (1999): “An interview on Minimalism. Noam Chomsky”, University of Siena, Nov. 8-9.

Chomsky, N. (1956): "Three Models for the Description of Language", IRE Transactions on Information Theory, II: 113-124.

Chomsky, N. (1957): Syntactic Structures (The Hague: Mouton). Cit. pola trad. de C. Otero, Estructuras sintácticas (Méjico: Siglo XXI, 1974).

Chomsky, N. (1965): Aspects of the Theory of Syntax (Cambridge, Mass.: The MIT Press). Cit. pola trad. de C. Otero. Aspectos de la teoría de la sintaxis (Madrid: Aguilar, 1971).

Chomsky, N. (1981): Lectures on Government and Binding (Dordrecht: Foris).

Chomsky, N. (1982): Some Concepts and Consequences of the Theory of Government and Binding (Cambridge, Mass.: The MIT Press). Cit. pola trad. de S. Alcoba / S. Balari, La nueva sintaxis. La teoría de la rección y el ligamiento (Barcelona: Paidós, 1988).

Chomsky, N. (1986): Knowledge of Language: Its Nature, Origins and Use (New York: Praeger). Cit. pola trad. de E. Bustos, El conocimiento del lenguaje. Su naturaleza, origen y uso (Madrid: Alianza, 1989).

Chomsky, N. (1993): “A Minimalist Program for Linguistic Theory”, en Hale, K. I Keyser, S. J. (coords.): The View from Building 20. Essays in Linguistics in Honor of Sylvain Bromberger: 1-52 (Cambridge, Mass.: The MIT Press). Trad. de J. Romero, "Un programa minimalista para la teoría lingüística", en $E l$ Programa Minimalista: 81-152 (Madrid: Alianza, 1999).

Chomsky, N. (1995): The Minimalist Program (Cambridge, Mass.: The MIT Press). Cit. pola trad. de J. Romero, El Programa Minimalista (Madrid: Alianza, 1999).

Chomsky, N. (1998): Una aproximación naturalista a la mente y al lenguaje (Barcelona: Prensa Ibérica).

Chomsky, N. (2000): "Minimalist Inquiries: The Framework", en Martin, R. / Michaels, D. / Uriagereka, J. (coords.): Step by Step. Essays on Minimalist Syntax in Honor of Howard Lasnik: 89-155 (Cambridge, Mass.: The MIT Press). Cit. pola trad. de V. M. Longa, "Indagaciones minimalistas: el marco", Moenia. Revista Lucense de Lingüística \& Literatura, 5, 1999: 69-126. 
Chomsky, N. / H. Lasnik (1977): "Filters and Control", Linguistic Inquiry, 8: 425-504.

Collins, C. (1997): Local Economy (Cambridge, Mass.: The MIT Press).

Culicover, P. (1998): "The Minimalist Impulse”, en Culicover, P. / McNally, L. (coords.): The Limits of Syntax. Syntax and Semantics 29: 47-77 (San Diego: Academic Press).

D’Introno, F. (1979): Sintaxis transformacional del español (Madrid: Cátedra).

D’Introno (2001): Sintaxis generativa del español: evolución y análisis (Madrid: Cátedra).

Hadlich, R. L. (1971): A Transformational Grammar of Spanish (New Jersey: PrenticeHall, Englewood Cliffs). Cit. pola trad. de J. Bombín, Gramática transformativa del español (Madrid: Gredos, 1973).

Hendrick, R. (1994): “The Brythonic Celtic copula and head raising”, en Lightfoot, D. / Hornstein, N. (coords.): Verb Movement: 163-188 (Cambridge: Cambridge University Press).

Huang, C.-T. (1995): "Logical Form", en Webelhuth, G. (coord.): Government and Binding Theory and the Minimalist Program: 127-175 (Oxford / Cambridge, Mass: Blackwell).

Kitahara, H. (1997): Elementary Operations and Optimal Derivations (Cambridge, Mass.: The MIT Press).

Longa, V. M. (1999): "The status of transformations in the Minimalist Program and the logical problem of language acquisition: an apparent disagreement", Theoretical Linguistics, 25: 161-178.

Longa V. M. (2001): "Minimalismos y Gramática Universal: un nuevo carácter para la facultad del lenguaje", en Abuín, A. / Casas, J. / González Herrán, J. M. (coords.): Homenaje al Profesor Benito Varela Jácome: 321-345 (Santiago de Compostela: Servicio de Publicacións).

Longa, V. M. / G. Lorenzo (2001): Derivación y representación: su alternancia cíclica en la teoría de la gramática (Noia: Toxosoutos).

Longa, V. M. / G. Lorenzo (no prelo): "Movimiento nuclear y economía: valor de la concordancia y movilidad de los clíticos en los Romances Occidentales", Verba.

Lorenzo, G. (no prelo): Comprender a Chomsky. Introducción y comentarios a la filosofía chomskyana sobre el lenguaje y la mente (Madrid: Antonio Machado Libros).

Lorenzo, G. / V. M. Longa (1996): Introducción a la sintaxis generativa (Madrid: Alianza).

Newmeyer, F. (1996): Generative Linguistics. A Historical Perpective (London / New York: Routledge). 
Radford, A. (1981): Transformational Syntax (Cambridge: Cambridge University Press). Cit. pola trad. de R. Cerdà, Introducción a la sintaxis transformativa (Barcelona: Teide, 1988).

Rizzi, L. (1982): Issues in Italian Syntax (Dordrecht: Foris).

Roberts, I. (1991): “Excorporation and minimality”, Linguistic Inquiry, 22: 209-218.

Rouveret, A. (1992): "Clitic Placement, Focus and the Wackernagel Position in European Portuguese", relatorio presentado no ESF Workshop on Clitics, Donostia.

Silva-Villar, L. (1998): "Subject positions and the roles of CP”, en A. Schwegler, A. I Tranel, B. / Uribe-Extebarria, M. (coords.): Romance Linguistics: Theoretical Perspectives: 247-270 (Amsterdam / Philadelphia: John Benjamins).

Zwart, J.-W. (1998): "Where is Syntax? Syntactic Aspects of Left Dislocation in Dutch and English", en Culicover, P. / McNally, L. (coords.): The Limits of Syntax. Syntax and Semantics 29: 365-393 (San Diego: Academic Press). 